\title{
Serum S100B is increased during early treatment with antipsychotics and in deficit schizophrenia
}

\author{
Matthias L. Schroeter ${ }^{\mathrm{a}, \mathrm{b}, *}$, Hashim Abdul-Khaliq ${ }^{\mathrm{c}}$, Stephan Frühauf ${ }^{\mathrm{a}}$, Ruth Höhne ${ }^{\mathrm{a}}$, \\ Gabi Schick $^{\mathrm{a}}$, Albert Diefenbacher ${ }^{\mathrm{a}}$, Ingolf E. Blasig ${ }^{\mathrm{b}}$ \\ a Department of Psychiatry, Queen-Elisabeth-Hospital, 10362 Berlin, Germany \\ ${ }^{\mathrm{b}}$ Institute of Molecular Pharmacology, 10315 Berlin, Germany \\ ${ }^{\mathrm{c}}$ German Heart Center Berlin, 13353 Berlin, Germany
}

Received 2 February 2002; accepted 1 August 2002

\begin{abstract}
Previous studies reported controversial results concerning alterations of astrocytes in schizophrenia. Because S100B may be regarded as a marker for astrocytes, the objective of this study was to examine S100B serum concentrations in 30 patients with schizophrenia with a monoclonal two-site immunoluminometric assay that specifically detects S100B. An ANOVA revealed medication $(p<0.005)$ and deficit vs. nondeficit syndrome $(p<0.05)$ as factors that influenced S100B significantly. S100B was higher in schizophrenic patients treated with antipsychotic drugs for approximately 3 weeks $(241.1 \pm 152.5 \mathrm{ng} / \mathrm{l}) \mathrm{in}$ comparison with unmedicated patients $(111.4 \pm 31.8 \mathrm{ng} / \mathrm{l}, p<0.005)$, and healthy age-matched controls $(112.8 \pm 53.4 \mathrm{ng} / 1, p<0.001$; Bonferroni corrected two-tailed Student's $t$-test). There was no difference of S100B between unmedicated patients and controls $(p>0.05)$. Patients with deficit $(250.6 \pm 154.9 \mathrm{ng} / \mathrm{l})$ had higher S100B levels than patients with nondeficit schizophrenia $(146.7 \pm 107.2 \mathrm{ng} / 1, p<0.05)$ or controls $(p<0.005)$. S100B was positively correlated with the subscore 'thought disturbance' of the Brief Psychiatric Rating Scale $(p<0.05)$. In summary, increased serum levels of S100B may indicate alterations of astrocytes during early treatment with antipsychotics and in deficit schizophrenia. Whether S100B is elevated due to injured astrocytes and a disrupted blood-brain barrier, or by active secretion of S100B by astrocytes, has to be clarified by further studies.
\end{abstract}

(C) 2002 Elsevier Science B.V. All rights reserved.

Keywords: Antipsychotics; Astrocytes; Deficit syndrome; S100B protein; Schizophrenia; Thought disturbance

\section{Introduction}

S100 proteins are a family of acidic proteins that can bind calcium and thus influence several cellular

\footnotetext{
${ }^{*}$ Corresponding author. Max-Planck-Institute of Cognitive Neuroscience, Stephanstr. 1A, 04103 Leipzig, Germany. Tel.: +49-341-9940-207; fax: +49-341-9940-221.

E-mail address: schroet@cns.mpg.de (M.L. Schroeter).
}

responses along the calcium-signal-transduction pathway (Schäfer and Heizmann, 1996). The monomer $\mathrm{S} 100 \mathrm{~B}$ is found in the central nervous system, especially in the cytoplasm of astrocytes. It can form homo- or heterodimers with S100A1. Each monomer has a molecular weight of approximately $10 \mathrm{kDa}$. S100B regulates cell shape, energy metabolism, contraction, cell-to-cell communication, intracellular signal transduction, cell growth (Zimmer et al., 1995), 
and can be released by astrocytes (Pinto et al., 2000). Interestingly, the effects of extracellular S100B depend on its concentration (Schäfer and Heizmann, 1996). Nanomolar concentrations act as growth and/or differentiation factor for neurons and astrocytes, whereas micromolar concentrations may induce apoptosis, for instance in pheochromocytoma cells. Serum concentration of $\mathrm{S} 100 \mathrm{~B}$ has been used as a marker for structural damage to the brain, particularly to astrocytes, for instance after cardiopulmonary bypass surgery (Abdul-Khaliq et al., 1999, 2000).

It is known that serum levels of S100B are elevated in untreated patients with schizophrenia in comparison with healthy controls (Lara et al., 2001; Rothermundt et al., 2001). However, the impact of antipsychotic medication on S100B is controversial. Increased (Wiesmann et al., 1999) and decreased levels (Gattaz et al., 2000) of S100B were reported in medicated schizophrenic patients in comparison with healthy controls. Further, Rothermundt et al. (2001) showed that treatment with antipsychotics for 6 weeks reduced S100B in this subgroup of patients, which had less negative symptoms, whereas S100B was unchanged in the subgroup with more negative symptoms at admission and after 6 weeks treatment. Therefore, we investigated the impact of medication on serum levels of S100B in a larger sample of schizophrenic patients. Negative symptoms that occur especially in the deficit syndrome influence S100B (Kirkpatrick et al., 2001; Rothermundt et al., 2001). Thus, the deficit syndrome was included as an additional factor in the analysis.

\section{Methods}

The patients consisted of 30 Caucasian subjects with schizophrenia (16 female, 14 male; 16 medicated, 14 drug-free), who were treated as inpatients in the Department of Psychiatry of a University affiliated hospital. Schizophrenia was diagnosed independently by two psychiatrists according to the criteria of the diagnostic and statistical manual of mental disorders (DSM-IV; American Psychiatric Association, 1994) and the international classification of diseases (ICD10; World Health Organization, 1993). The semistructured interview according to the AMDP-system (Arbeitsgemeinschaft für Methodik und Dokumenta- tion in der Psychiatrie) and ICD-10 checklists were used for diagnosis (Haug and Stieglitz, 1997). Systemic diseases (neoplasms, autoimmune diseases, infectious diseases and cardiovascular and neurological diseases) were ruled out by taking a detailed history, reviewing charts, physical examination and measuring the body temperature, C-reactive protein and erythrocyte sedimentation rate. Further, subjects were controlled for drug and alcohol abuse. Fifteen healthy Caucasian subjects (seven female, eight male) were recruited from the medical personnel as controls. Disorders as mentioned above and psychiatric disorders were excluded by taking a detailed history. Controls did not take any drugs.

There was no statistically significant difference between the mean age of patients $(34.8 \pm 12.4$ years $)$ and controls (34.2 \pm 5.6 years; two-tailed Student's $t$ test $T=0.22, p>0.05)$. Schizophrenia was characterized on average by a total lifetime duration of $8.9 \pm 8.8$ years and a number of $8.1 \pm 7.6$ episodes. The mean age at onset of first episode was $25.3 \pm 9.7$ years. The severity of schizophrenic symptoms was assessed with the Brief Psychiatric Rating Scale (BPRS; Overall and Gorham, 1962; Collegium Internationale Psychiatriae Scalarum, 1996). The total BPRS score was on average $45.3 \pm 12.6$. The deficit syndrome was determined according to the criteria by Kirkpatrick et al. (2001). Patients with schizophrenia were treated according to the guidelines of the American Psychiatric Association (1997) and the expert consensus guidelines for the treatment of schizophrenia (McEvoy et al., 1999). Medicated schizophrenic patients received typical (flupentixol, fluphenazine, haloperidol, perazine, pimozide, zuclopenthixol; $N=7$ ), atypical (amisulpiride, clozapine, olanzapine, risperidone, sulpiride; $N=4$ ), or both kinds of antipsychotics $(N=5)$, on average $363.1 \pm 248.8 \mathrm{mg}$ chlorpromazine equivalents/day (no difference between groups; ANOVA $d f=2, F=3.7, p>0.05)$. Atypical drugs were administered, when typical agents led to severe extrapyramidal symptoms, when symptoms did not respond to typical drugs and when a high amount of negative symptoms was present. Patients treated with atypical agents alone did not receive typical ones before. Patients were treated on an average of $20.9 \pm 24$ days $(N=14)$ before the determination of S100B; only two patients were medicated for more than 8 months before S100B was determined 


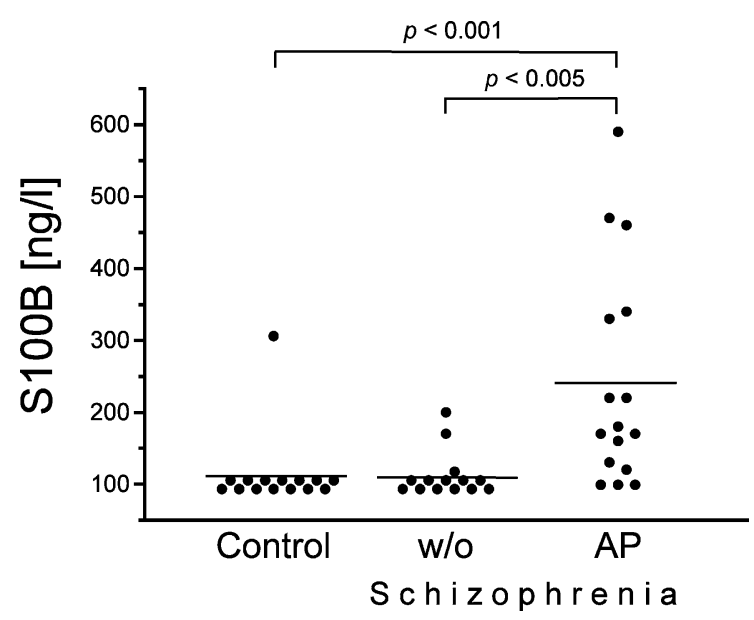

Fig. 1. Serum concentrations of $\mathrm{S} 100 \mathrm{~B}$ in 15 healthy controls (Control; $112.8 \pm 53.4 \mathrm{ng} / \mathrm{l}), 14$ unmedicated schizophrenic patients (w/o; $111.4 \pm 31.8 \mathrm{ng} / \mathrm{l}$ ) and 16 schizophrenic patients treated with antipsychotic drugs (AP; $241.1 \pm 152.5 \mathrm{ng} / \mathrm{l})$. Significance values were calculated by Bonferroni corrected two-tailed Student's $t$-test.

(no difference between medication groups; $d f=2$, $F=0.93, p>0.05)$. The investigation was carried out in accordance with the latest version of the Declaration of Helsinki. After complete description of the study to the subjects, a written informed consent was obtained. The research protocol was approved by the local ethics committee.

Blood samples were obtained by venipuncture performed at 8 a.m. Within $2 \mathrm{~h}$, the serum samples were centrifuged $\left(2{ }^{\circ} \mathrm{C}, 3500 \mathrm{rpm}, 10 \mathrm{~min}\right)$, and stored at $-70{ }^{\circ} \mathrm{C}$ until analysis. Serum concentrations of S100B were determined with a monoclonal two-site immunoluminometric assay (LIA-mat BykSangtec-100, AB Sangtec Medical, Bromma, Sweden; sandwich principle). The detection limit of the assay was $100 \mathrm{ng} / \mathrm{l}$. Values below $100 \mathrm{ng} / \mathrm{l}$ were reported as $99 \mathrm{ng} / \mathrm{l}$. Data are reported as mean \pm S.D. Serum concentrations of S100B were analyzed with an ANOVA, including medication, and deficit vs. nondeficit syndrome as main factors. Thereafter, groups were compared post hoc with two-tailed Student's $t$ test. Significance values were adjusted for multiple comparisons according to Bonferroni. Concerning medication, the respective treatment 3 days before the determination of $\mathrm{S} 100 \mathrm{~B}$ was considered, assuming a delay of the medication effect. A stepwise multiple regression analysis was performed to analyze whether
S100B was related to the severity of schizophrenia, age, total lifetime duration of the disorder, the number of episodes and age at onset of first episode.

\section{Results}

The ANOVA revealed medication $(d f=1, F=11.68$, $p<0.005)$ and deficit vs. nondeficit syndrome $(d f=2$, $F=5.09, p<0.05)$ as factors that influenced serum concentrations of S100B significantly. There was no significant interaction between these factors $(d f=2$, $F=2.4, p>0.05)$. To further assess the impact of medication (Fig. 1), unmedicated, medicated patients and healthy controls were compared post hoc with Student's $t$-tests. S100B was significantly higher in schizophrenic patients treated with antipsychotic drugs $(241.1 \pm 152.5 \mathrm{ng} / \mathrm{l}, N=16)$ than in unmedicated patients $(111.4 \pm 31.8 \mathrm{ng} / \mathrm{l}, N=14 ; p<0.005)$ and healthy controls $(112.8 \pm 53.4 \mathrm{ng} / \mathrm{l}, \quad N=15$; $p<0.001)$. However, there was no statistically significant difference between untreated patients and controls $(p>0.05)$.

The ANOVA revealed a significant effect of the deficit syndrome on serum concentrations of S100B. As illustrated in Fig. 2, patients with deficit schizophrenia $(250.6 \pm 154.9 \mathrm{ng} / \mathrm{l}, N=12)$ had significantly

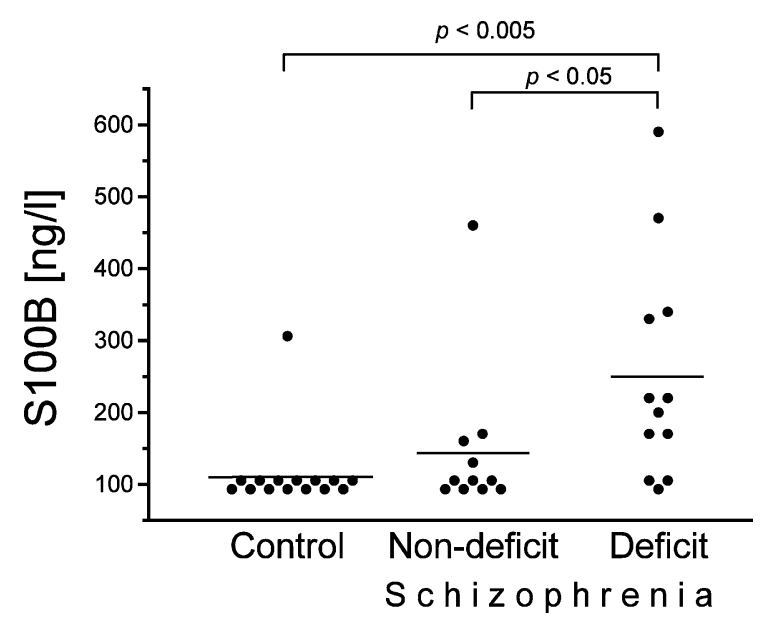

Fig. 2. Serum concentrations of S100B in 15 healthy controls $(112.8 \pm 53.4 \mathrm{ng} / \mathrm{l}), \quad 11$ patients with nondeficit schizophrenia $(146.7 \pm 107.2 \mathrm{ng} / \mathrm{l})$ and 12 patients with deficit schizophrenia $(250.6 \pm 154.9 \mathrm{ng} / \mathrm{l})$. Significance values were calculated by Bonferroni corrected two-tailed Student's $t$-test. 
Table 1

Factors that influenced serum concentrations of S100B (multiple regression analysis)

\begin{tabular}{lcc}
\hline Factor & Beta & $p$ \\
\hline Age & 0.065 & n.s. \\
Total lifetime duration of disorder & 0.203 & n.s. \\
Number of episodes & 0.325 & n.s. \\
Age at onset of first episode & -0.109 & n.s. \\
Total BPRS score & 0.391 & $<0.05$ \\
BPRS 1: anxiety/depression & 0.179 & n.s. \\
BPRS 2: anergia & 0.118 & n.s. \\
BPRS 3: thought disturbance & 0.363 & $<0.05$ \\
BPRS 4: activation & 0.17 & n.s. \\
BPRS 5: hostile-suspiciousness & 0.061 & n.s. \\
\hline
\end{tabular}

BPRS: Brief Psychiatric Rating Scale.

higher S100B levels than patients with the nondeficit form of the disease $(146.7 \pm 107.2 \mathrm{ng} / \mathrm{l}, N=11)$ and healthy controls $(p<0.05,<0.005$, respectively; Student's $t$-test). There was no significant difference between S100B concentration in nondeficit schizophrenia and healthy controls $(p>0.05)$. Patients suffering from schizophrenia with an uncertain course $(113.6 \pm 30.3 \mathrm{ng} / \mathrm{l}, N=7)$ were excluded from this comparison because illness duration was less than 1 year.

The multiple regression analysis demonstrated that S100B was related to the severity of schizophrenia (total BPRS score), whereas there was no effect of age, total lifetime duration of the disorder, the number of episodes and age at onset of first episode (Table 1). The regression analysis isolated the third BPRS subscore (thought disturbance) as the specific subscore that influenced serum concentrations of S100B significantly. The correlation between S100B and the third BPRS subscore remained also statistically significant when it was controlled for medication and deficit syndrome (two-tailed partial correlation $r=0.42, p<0.05$ ).

\section{Discussion}

Our results demonstrate that serum concentrations of S100B are higher in schizophrenic patients treated with antipsychotics when compared with unmedicated patients and healthy controls. Thus, the data suggest that antipsychotics increase serum concentrations of S100B. Astrocytes may actively secrete S100B (Pinto et al., 2000) and possess $D_{2}$ receptors, at least in specific brain regions (Khan et al., 2001). Because particularly typical antipsychotics act via $\mathrm{D}_{2}$ receptors (Kapur and Seeman, 2001), they may trigger elevations of the intracellular messenger cyclic adenosine 3',5'-monophosphate (cAMP) (Siegel et al., 1999). Astrocytes in turn may secrete S100B, induced for instance by the cAMP regulatory element (Zimmer et al., 1995; Pinto et al., 2000). This hypothesis may explain the higher serum levels of S100B in medicated patients in comparison with unmedicated patients and healthy controls in our study, particularly because the majority of patients received typical antipsychotics. Thus, our results are in accordance with Wiesmann et al. (1999) who showed elevated S100B levels in medicated schizophrenic patients compared with healthy controls.

On the other hand, our results are inconsistent with reports by Gattaz et al. (2000), which demonstrated reduced plasma levels of S100B in (mostly with clozapine) medicated schizophrenic patients compared with healthy controls. This difference might be explained by a different duration of antipsychotic treatment before the measurement of $\mathrm{S} 100 \mathrm{~B}$ in the studies. In our study, almost all patients were treated on an average of 3 weeks before the determination of S100B. Rothermundt et al. (2001) showed that treatment with antipsychotics for 6 weeks reduced S100B in this subgroup of patients, which had less negative symptoms, whereas S100B was unchanged in the subgroup with more negative symptoms at admission and after 6 weeks treatment. Thus, one may hypothesize that antipsychotics increase S100B during the first weeks of treatment, whereas in the long run, after more than 5 weeks, they decrease S100B, at least in patients with a small amount of negative symptoms. According to this hypothesis, Wiesmann et al. (1999) and our study measured elevated S100B during the first weeks of treatment, whereas Gattaz et al. (2000) and Rothermundt et al. (2001) measured decreased levels of S100B after more than 5 weeks of treatment, at least in patient subgroups.

Moreover, we demonstrate higher S100B levels in deficit than nondeficit schizophrenia, which corresponds to Rothermundt et al. (2001), reporting a correlation between S100B and negative symptomatology. The data may suggest that S100B serum levels are related to the deficit syndrome in schizophrenia, 
which was proposed to be a separate disease within the schizophrenic syndrome (Kirkpatrick et al., 2001). Further, we show a positive correlation between S100B and the severity of thought disturbance in schizophrenia, which was also found in depression with psychotic features (Schroeter et al., in press). Lara et al. (2001) and Rothermundt et al. (2001) reported higher serum levels of S100B in untreated patients with schizophrenia in comparison with healthy controls. On the contrary, we did not find such differences, presumably due to a higher detection limit in our study.

One might suppose that the three factors (medication, deficit syndrome and third BPRS subscore) that had an impact on serum levels of S100B in our study might be interrelated. Then, differences concerning medication might just be caused by differences in the deficit syndrome between medicated and unmedicated patients. However, the ANOVA revealed no interaction between the main factors medication and deficit syndrome. Further, the correlation between S100B and the third BPRS subscore remained significant after controlling for medication and deficit syndrome. Thus, medication, deficit syndrome and the third BPRS subscore seem to be independent factors influencing serum levels of S100B in schizophrenia.

Summarizing the data, increased serum levels of S100B may indicate alterations of astrocytes (Schäfer and Heizmann, 1996) in the deficit syndrome of schizophrenia, and during early treatment with antipsychotics. Whether S100B serum levels are elevated due to damage to the brain, particularly astrocytes (Abdul-Khaliq et al., 1999, 2000), and a subsequent disruption of the astrocytically supported blood-brain barrier (Schroeter et al., 1999, 2001), or by the active secretion of S100B by astrocytes (Pinto et al., 2000), has to be clarified by further studies.

\section{Acknowledgements}

The study was financially supported by BMBF, BEO 0311466c and DFG SFB 507 TPA2.

\section{References}

Abdul-Khaliq, H., Blasig, I.E., Baur, M.O., Hohlfeld, M., AlexiMeskhishvili, V.A., Lange, P.E., 1999. Release of the cerebral protein S-100 into blood after reperfusion during cardiac operations in infants: is there a relation to oxygen radical-induced lipid peroxidation? J. Thorac. Cardiovasc. Surg. 117, 1027-1028.

Abdul-Khaliq, H., Schubert, S., Stoltenburg-Didinger, G., Troitzsch, D., Bottcher, W., Hubler, M., Meissler, M., Grosse-Siestrop, C., Alexi-Meskishvili, V., Hetzer, R., Lange, P.E., 2000. Protein S100 beta in brain and serum after deep hypothermic circulatory arrest in rabbits: relationship to perivascular astrocytic swelling. Clin. Chem. Lab. Med. 38, 1169-1172.

American Psychiatric Association, 1994. Diagnostic and Statistical Manual of Mental Disorders, 4th ed. American Psychiatric Press, Washington, DC.

American Psychiatric Association, 1997. Practice guideline for the treatment of patients with schizophrenia. Am. J. Psychiatry 154 (Suppl. 4), 1-63.

Collegium Internationale Psychiatriae Scalarum (Eds.), 1996. Internationale Skalen für Psychiatrie. Beltz-Test, Göttingen.

Gattaz, W.F., Lara, D.R., Elkis, H., Portela, L.V., Goncalves, C.A., Tort, A.B., Henna, J., Souza, D.O., 2000. Decreased S100-beta protein in schizophrenia: preliminary evidence. Schizophr. Res. 43, 91-95.

Haug, J.H., Stieglitz, R.D. (Eds.), 1997. Das AMDP-System in der klinischen Anwendung und Forschung. Hogrefe, Göttingen.

Kapur, S., Seeman, P., 2001. Does fast dissociation from the dopamine $\mathrm{D}_{2}$ receptor explain the action of atypical antipsychotics? A new hypothesis. Am. J. Psychiatry 158, 360-369.

Khan, Z.U., Koulen, P., Rubinstein, M., Grandy, D.K., GoldmanRakic, P.S., 2001. An astroglia-linked dopamine $\mathrm{D}_{2}$-receptor action in prefrontal cortex. PNAS 98, 1964-1969.

Kirkpatrick, B., Buchanan, R.W., Ross, D.E., Carpenter, W.T., 2001. A separate disease within the syndrome of schizophrenia. Arch. Gen. Psychiatry 58, 165-171.

Lara, D.R., Gama, C.S., Belmonte-de-Abreu, P., Portela, L.V.C., Goncalves, C.A., Fonseca, M., Hauck, S., Souza, D.O., 2001. Increased serum S100B protein in schizophrenia: a study in medication-free patients. J. Psychiatr. Res. 35, 11-14.

McEvoy, J.P., Scheifler, P.L., Frances, A., 1999. The expert consensus guideline series: treatment of schizophrenia 1999. J. Clin. Psychiatry 60 (Suppl. 11), 1-80.

Overall, J.E., Gorham, D.R., 1962. The Brief Psychiatric Rating Scale. Psychol. Rep. 10, 799-812.

Pinto, S.S., Gottfried, C., Mendez, A., Goncalves, D., Karl, J., Goncalves, C.A., Wofchuk, S., Rodnight, R., 2000. Immunocontent and secretion of S100B in astrocyte cultures from different brain regions in relation to morphology. FEBS Lett. 486, 203-207.

Rothermundt, M., Missler, U., Arolt, V., Peters, M., Leadbeater, J., Wiesmann, M., Rudolf, S., Wandinger, K.P., Kirchner, H., 2001. Increased S100B blood levels in unmedicated and treated schizophrenic patients are correlated with negative symptomatology. Mol. Psychiatry 6, 445-449.

Schäfer, B., Heizmann, C., 1996. The S100 family of EF-hand calcium-binding proteins: function and pathology. TIBS, 134-140 (Reviews).

Schroeter, M.L., Mertsch, K., Giese, H., Müller, S., Sporbert, A., Hickel, B., Blasig, I.E., 1999. Astrocytes enhance radical de- 
fence in capillary endothelial cells constituting the blood-brain barrier. FEBS Lett. 449, 241-244.

Schroeter, M.L., Müller, S., Lindenau, J., Wiesner, B., Hanisch, U.K., Wolf, G., Blasig, I.E., 2001. Astrocytes induce manganese superoxide dismutase in brain capillary endothelial cells. NeuroReport 12, 2513-2517.

Schroeter, M.L., Abdul-Khaliq, H., Diefenbacher, A., Blasig, I.E., 2002. S100B is increased in mood disorders and may be reduced by antidepressive treatment. NeuroReport 13 (in press).

Siegel, G.J., Agranoff, B.W., Albers, R.W., Fisher, S.K., Uhler, M.D. (Eds.), 1999. Basic Neurochemistry, 6th ed. LippincottRaven, Philadelphia, p. 252, 1061.
Wiesmann, M., Wandinger, K.P., Missler, U., Eckhoff, D., Rothermund, M., Arolt, V., Kirchner, H., 1999. Elevated plasma levels of S-100b protein in schizophrenic patients. Biol. Psychiatry 45, $1508-1511$

World Health Organization, 1993. The ICD-10 Classification of Mental and Behavioural Disorders: Diagnostic Criteria for Research (DCR). WHO, Geneva.

Zimmer, D.B., Cornwall, E.H., Landar, A., Song, W., 1995. The S100 protein family: history, function, and expression. Brain Res. Bull. 37, 417-429. 